\title{
LAS TAREAS LEXICOGRÁFICAS Y LOS ESTUDIOS SOBRE LÉXICO DE RAFAEL LAPESA
}

\author{
Pedro Álvarez de Miranda
}

El conoclmlento y la difusión de los trabajos que D. Rafael Lapesa ha dedicado al estudio del léxico español se han facilitado enormemente gracias a la publicación, en fechas aún relativamente cercanas, de tres volúmenes recopilatorios a los que habré de hacer continua referencia en estas páginas. Me refiero a los dos que, bajo el título general de Léxico e historia (/. Palabras, JI. Diccionarios), preparó y cuidó, en colaboración con el autor, el prof. Juan Ramón Lodares ${ }^{1}$ y al largamente esperado que con el título El español moderno y contemporáneo. Estudios lingüísticos vio la luz pocos años después ${ }^{2}$. No es que el conjunto de la producción lapesiana que aquí será objeto de comentario se agote en lo recogido en tales volúmenes (pues a ello hay que agregar por lo pronto, y como enseguida veremos, los frutos mismos de la dedicación del autor a tareas estrictamente lexicográficas $)^{3}$, pero queríamos comenzar señalando esta feliz circunstancia - que esperamos ver pronto extendida a otros sectores de la obra del maestro, y muy en particular al nutridísimo de la sintaxis-, enormemente facilitadora del trabajo frente al inevitable periplo bibliográfico de acarreo que hubiera implicado realizar la tarea antes de 1992.

Por otra parte, en las páginas que siguen no agotaré el examen de las aportaciones de don Rafael Lapesa al conocimiento del léxico español, pues, lógicamente, muchos trabajos suyos, de historia lingüística y literaria, están salpicados de ellas. Trataré tan solo de no dejar fuera ninguna aportación en que el léxico haya ocupado exclusiva o sustancialmente la atención del autor.

Comenzaré por referirme a lo que, dentro del campo de los estudios léxicos, considero aspecto más destacado de la actividad lapesiana, que es el de su efectiva dedicación a tareas lexicográficas, y en especial su decisiva labor al frente del Diccionario histórico de la lengua española. Ese aspecto no ha solido figurar entre los más conocidos y apreciados de la tarea de Lapesa, hasta que un oportuno y --como suyo-excelente artículo de Manuel

\footnotetext{
${ }^{1}$ Madrid, Istmo, 1992. En adelante, $L H l$ y $L H 11$

${ }^{2}$ Barcelona, Crítica, 1996. En adelante, EMC.

${ }^{3} \mathrm{Y}$, por otro lado, $\boldsymbol{E M C}$ incluye trabajos que por su tema quedan fuera de nuestro cometido.
} 
Seco ha venido hace poco a destacarlo ${ }^{4}$. Inevitablemente, en lo que sigue, habré de remitir a él en más de una ocasión.

Tal vez no esté de más comenzar señalando que, en general, los grandes proyectos lexicográficos no se han visto muy favorecidos de la fortuna (o quién sabe si de la perseverancia) en el ámbito de la filología española de este siglo que termina; lo que casi equivale a decir: en el de esa escuela que encabeza la personalidad impar de don Ramón Menéndez Pidal y de la que don Rafael Lapesa ha venido a ser no solo miembro conspicuo y fidelísimo, sino en los últimos tiempos, hasta hoy mismo, indiscutible y venturosa cabeza viva.

El perfil positivista de la lingüística decimonónica favoreció, en los países donde esta alcanzó desarrollo, el acometimiento de empresas lexicográficas de gran aliento; frente a ello, la indisimulable penuria de nuestro siglo XIX nos dejó casi al margen de tal corriente, $y$, en medio de un panorama francamente desolador, hubo de alzarse la figura de Pidal como titánico arquitecto del edificio de la filología española. Era sencillamente imposible que él y el puñado de sus colaboradores del Centro de Estudios Históricos lo hicieran todo; que, enjugando el retraso secular, construyeran el edificio desde los cimientos a la cúspide. Pero no dejaron de intentarlo: desde luego, existía plena conciencia de la magnitud de la tarea y disponían de planos bien trazados. Faltaron obreros y energías, hubo, acaso, dispersión inevitable, y - lo peor de todo— faltó tiempo. La guerra civil fue una verdadera catástrofe, también para la filología española.

Después de la contienda, en plenitud de facultades intelectuales pero disgregado ya el equipo, un Menéndez Pidal de 76 años escribe una de las piezas doctrinales más enjundiosas que ha dado la no muy abundante reflexión lexicográfica en nuestra lengua; me refiero a "El diccionario que deseamos", extenso prólogo a un excelente diccionario manual cuidado por un discípulo de don Ramón, Samuel Gili Gaya ${ }^{5}$. El maestro convierte esas páginas en algo así como un testamento lexicográfico, aprovecha para pedir en ellas que se lleve a cabo un proyecto que, evidentemente, él ya no aspiraría a liderar: un diccionario total, con ambición de exhaustividad, de la lengua española. Leer hoy esas páginas de hace más de medio siglo es un amargo ejercicio, por la sencilla razón de que lo que en ellas se dice - se pide - se puede seguir suscribiendo hoy punto por punto. El diccionario que se deseaba en 1945 seguimos, por desgracia, deseándolo en 1999.

Tal vez lo que en esas páginas volcó don Ramón se pareciera bastante a lo que querría haber llevado a la práctica de no haber fracasado el efímero proyecto lexicográfico a cuyo frente había estado, por encargo de la editorial Calpe, en torno a $1920^{6}$. Pero es que,

\footnotetext{
4 “Las palabras bajo el microscopio", Ínsula, nº 616 [Dos maestros, número de homenaje a Rafael Lapesa y Pedro Laín Entralgo], abril de 1998, pp. 4-5.

${ }^{5}$ Vox, Diccionario general ilustrado de la lengua española. Pról. de D. Ramón Menéndez Pidal. Revisión de D. Samuel Gili Gaya. Barcelona, Spes, 1945. El prólogo se incluyó, con el título "El diccionario ideal", en Estudios de lingüística, Madrid, Espasa-Calpe, 1961, pp. 93-147.

${ }^{6}$ Américo Castro se refirió al proyecto en estos términos: "En un momento, además —en 1919-, nos embarcamos en la empresa colosal de armar un diccionario de la lengua como sólo él [Menéndez Pidal] podía
} 
además, otros proyectos parciales menos abarcadores, otras piezas del edificio, se habían quedado en el camino. Me refiero al glosario del español primitivo (es decir, a lo que tendría que haber sido el tomo II de Orígenes del español, proyecto al que Lapesa ha estado muy directamente vinculado durante - literalmente - toda su vida, y sobre el que, por tanto, luego he de volver) y al *Corpus Glossariorum que don Ramón encomendó a otro discípulo, precisamente a Gili Gaya ${ }^{7}$. En este caso, la idea — muy original— era refundir en una sola obra de consulta todos los diccionarios de español anteriores a Autoridades, y don Samuel la había acometido con brío; en 1936 estaban impresos los 20 primeros pliegos ${ }^{8}$, pero el primer fascículo no aparecería hasta 1947, ya bajo el sello editorial del C.S.I.C., con el título de Tesoro lexicográfico (1492-1726). Su interrupción diez años después, cuando la obra iba por la letra E, fue una calamitosa decisión ajena a la voluntad de Gili Gaya.

Por tradición, por la abundancia del material ya recopilado, la Real Academia Española era la institución más indicada para responder al reto planteado por Menéndez Pidal en 1945. Un académico que no procedía de su entorno, un lingüista autodidacto y excepcionalmente bien dotado para la lexicografía, Julio Casares, concibe la idea de un nuevo Dicionario histórico de la lengua española (otro iniciado por la misma corporación en 1933-36 valía más cancelarlo, y así se hizo), promueve la creación en el seno de ella de un centro de investigación, el Seminario de Lexicografía (fundado en 1946), y publica un libro fundamental y fundacional, la Introducción a la lexicografía moderna (1950), donde traza las líneas maestras del proyecto, muy directamente inspirado en el mejor modelo posible, el diccionario inglés de Oxford.

Son hechos, los que estoy recordando, suficientemente conocidos, y no es este el momento de reconstruir la trayectoria de un proyecto, el del DHLE, que ha dado hasta el momento unos frutos de extraordinaria calidad aunque, por desgracia, cuantitativamente menguados: 23 fascículos que cubren las dos terceras partes de la letra A y el comienzo de la B. Sí lo es, en cambio, de subrayar la decisiva contribución de Rafael Lapesa a esa magna obra hoy —ojalá que no definitivamente— paralizada.

Pues, en efecto, Lapesa, con su talante siempre integrador, fue persona clave en la puesta en práctica del proyecto de Casares, al que aportó las señas de identidad de la

concebir y dirigir. La ambiciosa empresa se vino abajo, porque a la hora de la verdad éramos únicamente dos o tres los decididos y capacitados para llevarla a término. Esto hubiera supuesto, para don Ramón y para nosotros, veinte o treinta años de labor, a ocho horas de peonada diaria, porque los diccionarios a mano eran insuficientes. Aspirábamos a dar el diccionario total de la lengua castellana en todos sus mundos, con rigor exacto y con criterio orientador para el hablante y para el escritor, con etimologías y con autoridades. Todos éramos españoles, y pensábamos que las cosas se hacen o no se hacen. «Tot o res»..." ("Cuánto le debemos", Papeles de Son Armadans, no 39, junio de 1959, pp. 288-289). Véanse también J. Pérez Villanueva, Ramón Menéndez Pidal. Su vida y su tiempo, Madrid, Espasa-Calpe, 1991, pp. 299-300, y J. I. Pérez Pascual, Ramón Menéndez Pidal. Ciencia y pasión, Valladolid, Junta de Castilla y León, 1998, p. 170.

${ }^{7}$ Cf. Diego Catalán, Lingüística ibero-románica. Crítica retrospectiva, Madrid, Gredos, 1974, pp. 72 y 260-261.

${ }^{8}$ Cf. R. Lapesa, "Menéndez Pidal, creador de escuela: el Centro de Estudios Históricos", en jAlça la voz, pregonero! Homenaje a don Ramón Menéndez Pidal, Madrid, Cátedra-Seminario Menéndez Pidal, 1979, pp. 64-66. 
escuela en que se había formado, y muy en particular una determinante: el rigor filológico. Don Rafael, que, recién terminada su licenciatura —con 19 años-, ya había colaborado durante un breve período (verano de 1927) en las tareas del primer Diccionario histórico ${ }^{9}$, ingresó en el recién creado Seminario de Lexicografía en 1947, y tres años después, ya académico electo, fue nombrado Subdirector de él. Director titular no lo fue hasta 1969 , pero importa subrayar que, según testimonios plenamente autorizados, lo venía siendo de facto desde mucho antes. Uno de esos testimonios es de Dámaso Alonso, y corresponde a 1962:

De heroica puede calificarse también su colaboración [de Lapesa] en el Diccionario Histórico de la Lengua Española, de la Real Academia Española; en esta gran obra lleva Lapesa la dirección efectiva del equipo de colaboradores ${ }^{10}$.

El otro es de Manuel Seco, que ingresó en el Seminario por esas mismas fechas:

Lapesa, que durante toda su vida ha actuado con una modestia, una honradez y una generosidad que todos deberíamos imitar, siempre se ha negado a aceptar para sí el mérito exclusivo de haber edificado la metodología del Diccionario histórico, alegando que en ella trabajaron conjuntamente don Julio Casares, él mismo y don Salvador Fernández Ramírez - quien, en calidad de redactor jefe, participó activamente en las tareas del Seminario de 1.948 a 1960 —. Es justo hacerlo constar así, pero también es justo añadir que, por lo menos desde la publicación del primer fascículo del Diccionario, en 1960, la dirección efectiva de este corrió a cargo de Lapesa - yo soy testigo-, a pesar de que la dirección oficial estuvo en otras manos hasta 1968. Y estos años, de rodaje en buena medida, fueron decisivos para el perfilado y ajuste del plan en el paso del terreno proyecto al terreno realidad ${ }^{11}$.

\footnotetext{
${ }^{9}$ No resisto la tentación de reproducir aquí una deliciosa evocación que de esa primera experiencia nos ha dejado su protagonista: "En el verano de 1927, recién terminada mi licenciatura, don Vicente García de Diego, inolvidable maestro mío de Latín en el Instituto Cardenal Cisneros, me ofreció trabajar en el Diccionario Histórico que entonces empezaba a preparar la Academia. Acepté muy contento y vine durante algún tiempo hasta que en septiembre entré como becario en el Centro de Estudios Históricos. Mi quehacer en la Academia consistía en copiar con letra legible fichas previamente seleccionadas y clasificadas que, con ejemplos de diversos autores, respaldaban las definiciones de cada palabra o acepción. Mi mentor era un hombrecillo entrado ya en años, de mirada penetrante, benévola y a la vez irónica, que susurraba con aire de misterio consejos y observaciones. El señor Bueso, que así se llamaba aquel duende, se sorprendía cada vez que yo apuntaba dudas sobre el significado que se atribuía a algún ejemplo y apuntaba la posibilidad de otra interpretación. Y al fin, una vez, con acento aun más sibilino que de ordinario, musitó: «Usted será académico algún día». Naturalmente, yo lo tomé a broma y olvidé el augurio. Cuando veinte años después ingresé en el Seminario de Lexicografía ya no encontré al bondadoso gnomo; pero al ser elegido académico en 1950 comprendí que su vaticinio había sido además un embrujo. Y embrujado quedé a partir de entonces por la Academia y por su Diccionario Histórico..." ("Acción de gracias" [en el homenaje académico por sus 80 años], BRAE, LXVIII (1988), pp. 56-57). Como observa Seco, "lo más interesante de esta anécdota no es el vaticinio en sí, sino la realidạd que lo había motivado: el ojo clínico para penetrar en el significado allí donde sin duda personas más expertas no habían dado con el análisis preciso" (art. cit., p. $5 a$ ).

10 "Nota de 1962" a "Rafael Lapesa en la Academia", texto del discurso de contestación al de ingreso de Lapesa en la Academia (1954), en Del Siglo de Oro a este siglo de siglas, Madrid, Gredos, 1962, p. 216.

${ }^{11}$ Art. cit., p. $5 a$.
} 
Es también sumamente significativo que desde temprana fecha fuera Lapesa el encargado de presentar en diversos foros internacionales el proyecto del DHLE. De 1956 es su ponencia ante el Segundo Congreso de Academias de la Lengua Española, celebrado en Madrid: "Colaboración de las Academias de la Lengua al Diccionario Histórico" (LE II, pp. 19-23). Va encaminada, especialmente, a solicitar ayuda a las Academias americanas en el proceso de papeletización, en el suministro de libros y en todo lo relacionado con los americanismos del DHLE. Pero no solo con ellos; como Lapesa inteligentemente advierte, "el interés no se limita a las palabras o acepciones exclusivas o características del español hablado en Hispanoamérica, en alguno de sus países o en Filipinas; nos interesan igualmente ejemplos americanos y filipinos de los usos comunes en el español de España" (p. 22). El diccionario en el que se trabajaba debía ser armónicamente panhispánico.

Al año siguiente, 1957, el Centre National de la Recherche Scientifique de Francia convoca en Estrasburgo una importante reunión de expertos, exploratoria de las posibilidades de lo que acabaría siendo el Trésor de la langue française. Lapesa acude a ella y, ante los máximos representantes de la lexicografía románica (Wartburg, Migliorini, Imbs, Robert...), presenta su informe "Le dictionnaire historique de la langue espagnole" 12 . Fue la primera exposición sistemática de las características que había de tener el DHLE, y junto con el leído - en un momento de especial euforia, pues coincidía con la aparición del primer fascículo- ante el Tercer Congreso de Academias (Bogotá, 1960; texto en LE II, pp. 25-30), preludia lo que será el magistral prólogo de la obra, aparecido al concluirse el tomo I (1972) y redactado, aunque no firmado, por Lapesa (LE II, pp. 41-61).

A ese prólogo pertenecen unas palabras muy a menudo citadas, que expresan con toda sencillez la magnitud de la tarea: "Nuestro Diccionario pretende registrar el vocabulario de todas las épocas y ambientes, desde el señorial y culto hasta el plebeyo, desde el usado en toda la extensión del mundo hispánico hasta el exclusivo de un país o región, española o hispanoamericana, desde el más duradero hasta el de vida efímera..." (p. 44). Un planteamiento, como se ve, más ambicioso que el de la primera edición del diccionario de Oxford, pero anticipador de los criterios universalistas que esa magna obra ha adoptado para la segunda, y de la creciente atención de la lexicografía francesa a los usos de la Francophonie. Téngase en cuenta que una supuesta - y por lo demás inexistente en nuestro caso- batería de excelentes diccionarios parciales nunca invalidaría la necesidad del diccionario total, fruto no solo del acopio de una rica y variada información primaria (textual) y secundaria, sino de su ordenación e interpretación conjunta. Lapesa ha ilustrado varias veces con ejemplos la prodigiosa utilidad del DHLE para reunir materiales dispersos. "Según nuestros datos — escribe, por ejemplo, en el prólogo-, sólo Torres Villarroel da testimonios literarios de aconfitado y aconfitar, pero la lexicografía colombiana los registra en el Cauca, sea por existencia de un estado latente común, sea por poligénesis" (p. 48). Poligénesis, desde luego, será la explicación más plausible para las discontinuidades léxicas

\footnotetext{
${ }^{12}$ Lexicologie et lexicographie françaises et romanes. Orientations et exigences actuelles. Strasbourg, 12-16 Novembre 1957, París, C.N.R.S., 1961, pp. 21-27. En LE II, pp. 31-40, se ha publicado la versión original española (y de nuevo en $E M C$, pp. 180-188).
} 
cuando afecten a derivados como los del ejemplo, pero en otros casos habrá efectivamente de acudirse a la fecunda idea pidaliana, tan cara a Lapesa, del estado latente. Desde las primeras páginas del diccionario llaman la atención ejemplos como el de "la exclamación $a b a, a b a ́$, en su acepción ponderativa o de sorpresa; registrada en la literatura religiosa popular del siglo XVI, aparece hoy conservada en tres rincones del mundo hispánico: los valles leoneses desde la Montaña hasta Zamora; el habla rural de San Luis, en el interior argentino, y en Filipinas como característica coloquial" ("Informe" de 1960, pp. 28-29). Para explicar, en fin, que abacorar 'acorralar', ampliamente documentada en el Caribe y con paralelo en Canarias, aparezca más tarde en "el habla actual de la montaña santanderina", Lapesa acude a un probable transplante por boca de indianos (ibíd., p. 28; el dato montañés procede de García-Lomas, cf. DHLE s. v.). En cualquier caso, el diccionario no va tan lejos en su interpretación: su misión es exponer --mas no comoquiera- los datos, y dejar al estudioso que saque sus propias conclusiones ${ }^{13}$.

Todo diccionario de gran envergadura, por muy planificado que esté cuando se acomete, ha de enfrentarse a un sinfín de problemas imprevistos, a una casuística interminable en el diseño de su macroestructura y su microestructura. Así le ha ocurrido, desde luego, al DHLE, que ha tenido que ir reajustando y puliendo sus métodos, primero con la guía de Lapesa, desde 1981 con la de su sucesor, Manuel Seco. Pero lo esencial está en el prólogo de 1972, que constituye en sí mismo un breve tratado de técnica lexicográfica sumamente útil, enfrentado a problemas en buena parte inéditos hasta entonces entre nosotros ${ }^{14}$. Quien lo lea con detenimiento y, además de ello, recorra atentamente las páginas de la obra, se hará cargo de la magnitud y complejidad de la empresa, también de su necesidad. "Aquí - escribe Seco- está la huella de Lapesa. En sus años de dirección del Diccionario histórico de la lengua española, Lapesa ha marcado con precisión los métodos para construir este inmenso registro de nuestras palabras"15. Permítaseme añadir, porque es de justicia hacerlo, que la huella de quien lo dice ha llegado a ser no menos visible en esta magna obra colectiva.

No se crea, sin embargo, que la labor de Lapesa fue solo de orientación y supervisión. Entregado personalmente a la redacción de dos artículos que por su envergadura arredrarían al más dispuesto, los correspondientes a alma y ánima, Lapesa decidió dar a conocer más ampliamente los frutos de su trabajo, llamar la atención de la comunidad científica, mediante ejemplos paradigmáticos, sobre la magnitud de la empresa, la riqueza de los resultados y su fecundidad teórica. Surgen así sus dos artículos (en acepción, ahora, no lexicográfica del término) "Alma y ámima en el Diccionario histórico de la lengua española" (1980) y "Alma y ánima en el Diccionario histórico de la lengua española: su fraseología” (1981) —ambos en LE II, pp. 65-86, y en EMC, pp. 189-206-, que

\footnotetext{
${ }^{13}$ Lapesa comenta otros casos similares a los aquí expuestos en su contestación al discurso de ingreso de Manuel Seco en la Academia (LH II, pp. 106-107).

${ }^{14}$ Sirva como botón de muestra el de las "palabras fantasma"; se explica en qué consisten, y el tratamiento que reciben, en p. 49

${ }^{15}$ Art. cit., p. $5 b$.
} 
despliegan y comentan ante el lector el precioso abanico histórico de tan polisémico doblete. El hecho de que para la redacción de alma tuviera que habérselas Lapesa con un total de "3.284 testimonios cuyas fechas van del año 1056 al 1977" (LH II, p. 65), de todos los rincones y estratos del idioma, da una idea de la complejidad del trabajo, que solo una inteligencia poderosa, entrenada, disciplinada ( $\mathrm{y}$, ni que decir tiene, humana) puede sacar adelante.

En el segundo de los trabajos citados hace Lapesa una enjundiosa reflexión teórica (ibíd., pp. 85-86) que arranca de una de las convicciones a que conduce el trato continuado con un rico material fraseológico: la paradójica falta de fijeza de las llamadas "expresiones fijas". Comienza así:

Las locuciones viven en variantes. No son "frases hechas", pues viven rehaciéndose en continua transformación, con innovaciones felices o torpes debidas a la iniciativa de colaboradores anónimos y aceptadas por un número más o menos amplio de hablantes. De las innumerables modificaciones que experimentan en el coloquio solo una parte mínima llega a la escritura. La fraseología es una de las manifestaciones primitivas — y a la vez más perdurables- de la creación artística de lenguaje transmitida por vía oral.

Desde este punto se accede inevitablemente, otra vez, a la apasionante cuestión de las continuidades y discontinuidades históricas:

Actividad y producto intermedio entre lo meramente lingüístico y las formas elementales de la literatura tradicional, la fraseología presenta, como estas, asombrosa continuidad en medio de su incesante renovación: son muchas las locuciones que se perpetúan con fluidez formal y aparición escrita ininterrumpida desde la Edad Media o el siglo XVI hasta ahora. Pero también hay casos de perduración en estado latente: las expresiones cidianas d'alma e de coraçón y "como a la mie alma yo tanto vos quería» no se repiten, que sepamos, en la literatura ni en los diccionarios españoles, pero subsisten hoy en las sefardíes de alma $i$ de korasón, lo kyero komo mi alma, recogidas por Nehama y Cantera. Los testimonios judeo-españoles actuales obligan también a suponer la existencia latente desde antes de 1492 para arrancársele el alma y estrechársele el alma a uno, cuya constancia escrita en España data de fines del siglo XVI y principios del siglo XVII respectivamente. A veces la locución que hubo de vivir soterrada desde antes de los Reyes Católicos asoma escrita con siglos de distancia y en los puntos más alejados del mundo hispánico: en 1593 Diego de Guadix dice en su Recopilación de nombres arábigos que al gato "se le sale el alma por pretender y tomar un ratón"; en 1891 el ecuatoriano González Suárez se refiere a alguien a quien "se le salía el alma viendo la comida"; y en 1977 Nehama y Cantera recogen "el alma l'está salyendo detrás de esta niña" como ponderación de lo que siente el enamorado. Sin testimonio judeo-español, la coincidencia en el uso de una locución entre España y América invita en ocasiones a considerarla muy anterior a las noticias que tenemos de ella: no caberle a uno el alma en el cuerpo 'estar muy inquieto y angustiado' consta como corriente en España y Argentina hacia 1920, en Chile desde 1945; y con el sentido de 'rebosar de alegría' hacia 1920 en España y desde 1953 en Colombia, donde tiene además la acepción de 'ser muy vivo', desconocida en España. El hecho de que ninguna de las tres zonas comparta todos los significados de la locución hace pensar en ramificaciones de un tronco existente desde muy atrás.

Y la excursión culmina con este hermoso cierre: 
Tradición oral, vida en variantes, estado latente; las doctrinas y métodos de Menéndez Pidal pueden iluminar de manera decisiva el estudio de la fraseología.

Se ha hablado a menudo, en relación con Lapesa, de fidelidad a una escuela. La clave está en no entender esa fidelidad como inmovilismo repetitivo, sino como incitación fecunda. Ojalá todas lo fueran tanto.

Ejemplo admirable de fidelidad es asimismo la continuada dedicación de Rafael Lapesa al proyecto que le puso por vez primera en contacto directo y cercano con su maestro. Ese proyecto, que se concibió inicialmente como un glosario de Orígenes del español, ha pasado por sucesivas etapas, y hoy parece estar próxima la publicación de una primera entrega que recoja la letra A, con el título definitivo de Glosario del primitivo léxico ibero-románico. No hace mucho, para conmemorar el 90 cumpleaños de don Rafael, la Fundación y el Seminario Menéndez Pidal han publicado un librito que explica la trayectoria del proyecto y reproduce algunos documentos de interés ${ }^{16}$. Así resume Diego Catalán los inicios de la empresa:

En aquel año [1926], Ramón Menéndez Pidal encargó a Pedro Sánchez Sevilla la papeletización de todas las voces que aparecían en sus Orígenes del español, con el fin de recoger ese léxico en un segundo volumen de la citada obra. Pero, pronto, don Ramón consideró conveniente ampliar los objetivos de esa publicación complementaria. Habiendo muerto, inesperadamente, Sánchez Sevilla, entró a substituirle en el "Centro de Estudios Históricos" Rafael Lapesa, y Menéndez Pidal le encargó, bajo su directa supervisión, inventariar todas las voces que aparecieran en documentos lingüísticos medievales desde el siglo IX al XI, siglos a los que se circunscribía el estudio de los Orígenes del español, aparecieran o no aparecieran en esta obra ${ }^{17}$.

El proyecto, como se ve, era del máximo interés: nada menos que elaborar el primero de una posible serie de diccionarios históricos secuenciales de la lengua española, dedicado este a la etapa de los primeros vagidos del idioma y previa recolección de cuantos testimonios total o parcialmente romances se hallaran en una gran masa documental mayoritariamente inédita.

Lapesa se empleó en la tarea hasta el comienzo de la guerra civil (la elaboración quedó entonces detenida en la letra $\mathrm{R}$ ), simultaneándola a partir de un determinado momento con la preparación, encargada también por don Ramón, de una Crestomatía del español medieval. La fundación del Seminario Menéndez Pidal en la Universidad de Madrid (1954) permitió la reanudación de ambas tareas: la Crestomatía apareció en 1965-66, acabada y revisada por Lapesa y Maria Soledad de Andrés, y en los trabajos del Glosario colaboraron esta última y Margarita Estarellas, además de Constantino García, de la Universidad de Santiago. De esta etapa salió una versión provisional completa que, con el título Glosario

\footnotetext{
${ }^{16}$ Glosario del primitivo léxico ibero-románico. Proyecto de informatización. Homenaje a Rafael Lapesa en sus noventa años, 8-II-1998. Madrid, 1998.

${ }^{17}$ Ibid., p. 37. El propio Lapesa ha contado con emoción y con humor sus primeros pasos en la tarea; vid su prólogo a J. Pérez Villanueva, Ramón Menéndez Pidal, pp. 11-12, o el tomito que acabamos de citar, pp. 13-16.
} 
del español primitivo, ha sido muy ampliamente utilizada para la redacción del DHLE por generosa cesión al Seminario de Lexicografía de una copia mecanoscrita.

Pero don Rafael Lapesa, siempre autoexigente, consideraba que la obra requería nueva revisión y aumento. Se iniciaron estos en 1987 gracias al patrocinio de las fundaciones Menénedez Pidal y Ramón Areces, con nuevos despojos documentales que ampliaron el marco cronológico al siglo XII. Tras ello, don Rafael, asistido desinteresadamente por el latinista Manuel Palomar Lapesa, consiguió dejar "casi definitivamente acabada la letra A de la obra”, y en 1998 el patrocinio de la Fundación Ramón Areces ha permitido poner en marcha "un proyecto de informatización del original disponible"18.

Las muestras que, en reproducción fotográfica, incluye el mencionado tomito de homenaje (los arabismos homónimos alfoz ${ }^{1}$ y alfoz ${ }^{2}$, andar y parte de su familia léxica ${ }^{19}$ ) no hacen sino aumentar los deseos de que la obra se publique y culmine. Presentan un original a máquina asaeteado por multitud de adiciones y correcciones manuscritas con la inconfundible y pulcra letra de Lapesa, y son un postrer testimonio de su laboriosidad y rigor, de todo un modo, artesanal y sabio, de hacer filología de alta calidad. Permiten, al mismo tiempo, hacerse una idea de la complejidad del trabajo: el lema de cada artículo va acompañado de la relación de todas las variantes fonéticas y gráficas de la palabra, con frecuencia numerosísimas, y seguido de la etimología y las diferentes acepciones con los correspondientes testimonios allegados, en orden cronológico.

Por los mismos años en que Lapesa se consagraba, en el Centro de Estudios Históricos, a la confección de este gran glosario, hubo de acometer otra tarea lexicográfica similar, pero a menor escala. En 1932 se publica por iniciativa municipal una cuidada edición del Fuero de Madrid (fines del s. XII-principios del XIII), que incluye, junto a una reproducción fotográfica del códice, su transcripción por Agustín Millares Carlo, un estudio histórico-jurídico a cargo de Galo Sánchez y un "Glosario" compilado por Lapesa ${ }^{20}$. En esa edición primera dicho glosario va precedido de una breve "Nota preliminar" sobre "Particularidades lingüísticas del Fuero de Madrid", pero en una nueva publicada treinta años después ${ }^{21}$ la nota se ha convertido en un mucho más extenso estudio: "El lenguaje del Fuero de Madrid"22. El glosario, sin embargo - que es lo que aquí nos concierne-, es sustancialmente el mismo en ambas ediciones, y un modelo en su género. Reúne los dos centenares largos de voces más interesantes del texto editado, con indicación de significados y - lo que lo avalora notablemente- con frecuente mención de otros testimonios antiguos, a menudo (pero no solo) extraídos de otros fueros. Algunos de los

${ }^{18}$ D. Catalán, ibíd., p. 41.

${ }^{19}$ Ibíd., pp. 45-50.

${ }^{20}$ Fuero de Madrid, Madrid, Artes Gráficas Municipales, 1932.

${ }^{21}$ Fuero de Madrid, Madrid, Ayuntamiento, 1963.

${ }^{22}$ Es lástima, por eso, que una tercera y más reciente reedición (Madrid, Ayuntamiento, 1994), al haber sido hecha facsimilarmente sobre la $1^{\text {a }}$ de 1932 , no recupere el estudio lapesiano de 1963 . El cual, no obstante, puede leerse también en los Estudios de historia lingüística española, Madrid, Paraninfo, 1985 (en adelante EHLE). 
términos a los que Lapesa hubo de enfrentarse le condujeron a más demoradas pesquisas, y fueron objeto de notas o pequeñas monografías etimológicas que nuestro autor publica por esas fechas, y que comentaremos enseguida.

Antes hemos de reseñar brevemente otros trabajos de Rafael Lapesa relacionados con la lexicografía española. Volviendo a la académica, recordaré aquí que nuestro autor conoce muy bien la evolución del llamado "diccionario común". Así se pone de manifiesto en un magistral panorama histórico sobre la trayectoria de la Docta Casa, trazado en 1987 ("La Real Academia Española: pasado, realidad presente y futuro", EMC, pp. 221-237), donde lamenta que el abandono, a partir de 1780, del método ejemplificador inaugurado por Autoridades supusiera "grave quebranto" para el valor documental del Diccionario. "A lo largo de sus diecinueve ediciones — ha escrito en otra ocasión-, nuestro Diccionario ha renovado - no siempre para mejorarlas- muchas definiciones del de Autoridades, ha duplicado el número de vocablos que registra y multiplicado el de sus acepciones. Pero queda mucho por actualizar y es infinito lo que hay que añadir." 23 De ahí que haya reclamado, siempre que ha tenido ocasión de hacerlo, el impulso para las tareas del DHLE como idóneo refundamentador del léxico oficial. Consciente, sin embargo, de que, aun con esa carencia, era posible la revisión y mejora del diccionario común, Lapesa ha seguido muy de cerca la aparición de sus sucesivas ediciones. Un trabajo de 1964, "Los diccionarios de la Academia" (LH II, pp. 13-18), está dedicado básicamente a comentar - de nuevo ante un Congreso de Academias - las novedades que iba a tener la 19ª , que no salió hasta 1970 pero se estaba imprimiendo desde 1963. Interesa conocer por él algunas interioridades (la revisión de las etimologías se encomendó a García de Diego y "todas las demás modificaciones" a Casares; las razones por las que se eliminaron los refranes ${ }^{24}$; etc.), como interesan los comentarios de Lapesa a algunas novedades que aquella edición presentó en la microestructura de los artículos. También concierne a las tareas académicas un discurso de Lapesa pronunciado en 1985, "Necesidad de una política hispánica sobre neologismos científicos y técnicos" (EMC, pp. 211-220), que aporta su lúcida visión de tan delicada cuestión presente, pero también esenciales precisiones del historiador sobre la lengua del pasado. Y ha de mencionarse, en fin - por más que la discreción del interesado la haya mantenido en absoluto silencio, diluida en el carácter colectivo de la empresa-, la activa intervención personal de don Rafael en la revisión del diccionario común para la edición actualmente vigente, la $21^{\text {a }}$ (1992).

Precisamente, con las limitaciones del diccionario común tiene mucho que ver un importante trabajo de Rafael Lapesa no recogido, por su fecha (1992), en Léxico e historia. Me refiero a "Sobre el concepto exclusivista del americanismo lingüístico: sus consecuencias en la lexicografía actual" 25 . Se aborda en él un tema crucial para la

\footnotetext{
${ }^{23}$ Contestación al discurso de ingreso de Fernando Lázaro Carreter, 1972 (LH II, p. 101).

${ }^{24}$ Esa acertada medida fue acompañada de la convocatoria de un concurso para recopilaciones paremiológicas, ganado por el Diccionario de refranes de Juana G. Campos y Ana Barella (Madrid, R.A.E., 1975); véase en LH II, pp. 87-89, el prólogo escrito por Lapesa para esta obra.

${ }^{25}$ Homenaje a Humberto López Morales, Madrid, Arco Libros, 1992, pp. 35-39.
} 
lexicografía hispánica: el de los diccionarios de americanismos, concebidos casi siempre como repertorios diferenciales, es decir, encargados de recoger usos léxicos no atestiguados en el español de España. El procedimiento sería aceptable si dispusiéramos de un diccionario fidedigno de ese "español de España", cosa que, desgraciadamente, no ocurre ${ }^{26}$. Como, curiosamente, la fe depositada en el diccionario académico va mucho más allá de lo que sus propios responsables desearían ${ }^{27}$, resulta que los repertorios de americanismos se pueblan de multitud de palabras y acepciones que son corrientes en la península, pero no aparecen registradas en el léxico oficial. Lapesa reprocha oportunamente a los autores de algunos repertorios de americanismos que no hayan tenido en cuenta el Diccionario manual de la propia Academia (que como se sabe cumplió entre otras, mientras existió, la misión de ser algo así como un banco de pruebas de su hermano mayor, y era más generoso que este con el neologismo), ni la parte publicada del Diccionario histórico. Así, por ejemplo, una muestra publicada - cuando Lapesa redactaba su trabajo- del hoy ya completo Nuevo diccionario de colombianismos dirigido por G. Haensch y $\mathrm{R}$. Werner ${ }^{28}$, dentro del vasto proyecto de un Nuevo diccionario de americanismos, suscita a Lapesa estas observaciones:

Aburrición 'aburrimiento' se da por inexistente en España, a pesar de que en el DRAE consta su uso familiar desde 1884, corroborado en el Diccionario Histórico de la Lengua Española (DHLE) con autoridades de Sbarbi y Pío Baroja y con testimonios de su empleo en Cádiz y Albacete. Tampoco es colombianismo ajeno al español peninsular el empleo de acompañamiento en la acepción de 'complemento o adorno comestible de un manjar', atestiguado también en el DHLE con ejemplos españoles de 1894, 1916 y 1962; es cierto que existe en España su sinónimo guarnición, pero con un uso menos general, más propio de las minutas de restaurante. El acusetas santandereano tiene su paralelo en el andaluz acuseta, acusetas, registrado por Alcalá Venceslada y por el DHLE. Agarradera es de empleo general en España como 'asa de la plancha o de una vasija', aunque el Diccionario común de la Academia restrinja tal acepción a Andalucía y América. Agripado es normal aquí como participio de agriparse, verbo documentado ya con un ejemplo de 1905 (pp. 37-38).

"El DRAE — comenta Lapesa-, por su desgracia, no es perfecto ni mucho menos; cuando lo que se busca falta realmente en él ${ }^{29}$, hay que consultar otras fuentes antes de declarar que no existe en el uso español" (p. 39). Cierto que el gran proyecto lexicográfíco promovido en Augsburgo por Haensch y Werner había previsto, y cumplió con ello, la consulta contrastiva a informadores españoles. Pero, realmente, cualquiera que recuerde aquello de Saussure (“... la lengua no está completa en ninguno, no existe perfectamente

\footnotetext{
${ }^{26}$ Pero está a punto de ocurrir, gracias al Diccionario del español actual de Manuel Seco y sus colaboradores, de inminente aparición cuando escribo estas líneas.

27 "Es tal la fe que ponen en el DRAE muchos usuarios suyos - escribe Lapesa-, que llegan a decir que tal o cual palabra corriente no «existe» por el mero hecho de no constar en él" (p. 36).

${ }^{28}$ Santafé de Bogotá, Instituto Caro y Cuervo, 1993.

${ }^{29}$ Como ese hasta luego' que decimos todos los españoles varias veces cada día y que, por increíble que parezca, faltaba en el diccionario común de 1984 y sigue faltando en el de 1992 (no así en el Diccionario manual de 1983-1985). Esa ausencia llevó a L. F. Lara a tenerlo por mexicanismo.
} 
más que en la masa") ¿se sentirá cómodo en el pellejo del más competente y bienintencionado de esos informantes?

En vista de lo dicho, Lapesa muestra su preferencia por los proyectos lexicográficos americanos que se proponen reflejar la totalidad del léxico empleado en los respectivos países o zonas, con independencia de que coincida o no con el uso peninsular (caso del proyecto titulado Estudio del español hablado culto, atento a las principales ciudades del mundo hispánico, o del de un gran Diccionario del español de México concebido por Luis Fernando Lara y aún no publicado). Comoquiera, es claro que Lapesa puso el dedo en la llaga al abordar esta cuestión. Desgraciadamente, un reciente y muy meritorio diccionario de americanismos realizado en Francia, que tiene la gran ventaja de ser un repertorio ejemplificado, sigue proclamando, incluso desde el título, su fe en el diccionario de la Academia como piedra de toque ${ }^{30}$, con lo que no solo nos sirve de nuevo como hispanoamericanos usos y voces que son igualmente españoles ${ }^{31}$, sino que sitúa al usuario en la paradójica circunstancia de disponer de documentación textual para los americanismos no registrados por la corporación y no para los que esta sír recoge.

\section{II}

La primera parte de LH I lleva el rótulo de "Etimologías" y recoge una serie de trabajos de Lapesa que se inscriben, en efecto, dentro del campo de la Etimología tanto en el sentido más restringido de esta (averiguación del origen de las palabras) como en el más lato (reconstrucción de su trayectoria histórica). Se encuentra entre ellos, por cierto, el más temprano de los que publicó (1930) ${ }^{32}$, "Derivados españoles de sulcus" (pp. 13-17), donde se estudian los sentidos de sulco, surco, suco (todos < lat. sulcus), en especial el de 'lindero', y también sus derivados y otras voces de significado próximo (derivados de

\footnotetext{
${ }^{30}$ Renaud Richard (coord.), Diccionario de hispanoamericanismos no recogidos por la Real Academia, Madrid, Cátedra, 1998.

${ }^{31}$ Veamos un par de ejemplos, entre muchos posibles. Sea uno el de bailongo 'baile', que el diccionario de Richard localiza en Argentina y Costa Rica y que en $D H L E$ no lleva localización geográfica, pues parece común a todo el mundo hispánico: ofrece para esa acepción nada menos que seis testimonios (del argentino Payró, del español García Hortelano, del chileno Lafourcade, del cubano Lezama Lima, del peruano Bryce Echenique...), el más antiguo de 1906, e informa de que en los ficheros académicos hay otros 24 textos más. Tampoco lleva localización la palabra, por cierto, en el diccionario común de 1992, primero de su serie en recogerla (ya estaba, no obstante, en el Manual de 1983-85); parece que su inclusión en este Diccionario de hispanoamericanismos se deberá, entonces, a discrepancia con la definición que da la Academia (1992) a la acepción que nos interesa: "baile de poca estimación", pues sus responsables precisan: "Baile; puede tener o no tener valor despectivo". DHLE confirma, en cierto modo, ambas cosas al definir así: "Baile. Frec. con intención desp. o jocosa" (la cursiva es mía). El otro ejemplo que queríamos exponer es el de bacalao 'persona flaca', referido frecuentemente a mujer para ponderar su fealdad, según DHLE; el diccionario común no recoge esta acepción (aunque a cambio casi nos da s. v. la receta del bacalao al pil-pil...), ejemplificada por aquel nada menos que con textos del Quijote, Castillo Solórzano, Salas Barbadillo y Clarín, y documentada con repertorios de aquí y de allá: Argentina, Ecuador, Cuba, Chile, Navarra, una cédula académica de Ruiz Morcuende... Tras de lo cual, el que Richard y sus colaboradores la registren en Puerto Rico y Cuba no es, desde luego, muy relevante.
}

${ }^{32}$ Sin contar una reseña de 1929, aparecida también — como el artículo a que me refiero- en la $R F E$. 
latus, como aledaño; de frons, como frontera y frontero; de limes, como linde y lindero) con las correspondientes zonas de extensión geográfica; de modo que, como se puede apreciar, la perspectiva no es solo semasiológica sino también onomasiológica. Sorprenden ya en esta temprana aportación, publicada a los 22 años, la riqueza de la documentación medieval manejada, la perfecta integración de la perspectiva dialectal en la historia de la lengua y, desde luego, un rasgo que a partir de este momento acompañará siempre al autor: la gran claridad expositiva.

Del año siguiente, 1931, es el primero de una serie de artículos misceláneos que podemos describir como manojillos de nótulas léxicas, un subgénero frecuente en las revistas filológicas surgidas de la gran tradición decimonónica, y en el que todo investigador solvente había de probarse. Esta primera entrega lleva por título "Notas para el léxico del siglo XIII" (pp. 19-26), y es un conjunto de micrografías dedicadas a explicar otras tantas formas difíciles u oscuras (hápax, algunas de ellas) documentadas en Berceo o en Santa María Egipciaca. Otra de 1936, "Notas etimológicas" (pp. 31-40), aparecida también en la espléndida $R F E$ de la anteguerra, tiene parecido carácter: aclaración de tal o cual vocablo del Fuero de Madrid o del Libro de Buen Amor, más, en este caso, la reconstrucción impecable de toda una familia léxica, la de rebollar, rebollo, repollo, pimpollo. Téngase en cuenta que, como ha escrito Diego Catalán, "la publicación del diccionario de W. Meyer-Lübke (REW, 1911-1920) dio ocasión a los filólogos del Centro [...] [Castro, García de Diego, Menéndez Pidal] para contribuir con toda una serie de suplementos, puramente hispánicos, a aquella gran empresa del comparatismo románico, que en el campo del español resultaba ser bastante deficiente"33; en una línea similar se sitúan estos trabajos juveniles de Lapesa, que se muestra en ellos romanista avezado y seguro. Junto al rigor, resulta muy de agradecer su prudencia, tan frecuentes como han llegado a ser los saltos mortales en la indagación etimológica.

A diferencia de García de Diego, ni Pidal, ni Castro, ni el mismo Lapesa hicieron de los estudios etimológicos el centro de sus investigaciones, pero - y cito nuevamente a Catalán, quien aplica su observación tan solo a los dos maestros de don Rafael, pero es perfectamente extensible a este- "en más de una ocasión, volverían a producir notas etimológicas, como cosecha lateral de sus trabajos filológicos y dialectales" 34 . Esa vuelta se produce en el caso de Lapesa al cabo de más de treinta años, pues sus "Notas lexicológicas" (pp. 45-51) son de 1968; en una de ellas apuntala con un dato histórico la etimología de bigote; en otra, con probidad característica, se corrige a sí mismo parcialmente — vuelve, con un nuevo testimonio, enlés (< en ille ipse), sobre las formas enés, ennesse, ennessos, estudiadas ya por él en 1936-; etcétera. En "Español antiguo linencia, linenciar, linencioso" (pp. 57-63), de 1980, se ensaya una explicación etimológica de linencia 'daño, lesión' (tal vez de un *lenigentia, deformación de negligentia) frente a la ofrecida previamente por Gorosch para esta voz de frecuente aparición en los fueros. Y, en fin, una nueva miscelánea (1988), "Notas etimológicas y semánticas" (pp. 65-77), reúne tres

\footnotetext{
${ }^{33}$ Lingüística íbero-románica, pp. 69-70.

${ }^{34}$ Ibíd., p. 70.
} 
monografías breves: sobre cabillo, capillo, 'cabildo', sobre compaña y compane y sus derivados y sobre encobarse 'concebir, empreñarse'.

En mi sentir, la pieza maestra de todo este conjunto es un trabajo de 1992, es decir, de un Rafael Lapesa ya octogenario: "Chanzón, chanzoneta, chancha, chanza, chanzaina, chanfaina y sus derivados" (pp. 87-111). Y lo es porque desenreda con suma pericia la trayectoria de un racimo de formas que tienen hasta cuatro distintos orígenes: 1. chançón I chanzón y chançoneta / chanzoneta, de ascendencia francesa o provenzal (chanson, chansonnette, chansoneta) y cuyos significados, que giraron primero en torno a la idea de 'canción festiva o burlesca', derivaron en 'burla, broma, pulla': desde el siglo XVI abundan las muestras de una chanzoneta —chanzón se usó muy poco- no musical ni versificada; 2. chancha 'embuste, mentira, engaño', del italiano ciancia; 3. chança / chanza, término de germanía, 'ingenio o astucia para hurtar', y de ahí chancero 'el astuto y que usa chanzas y sutilezas para hurtar', relacionados con fr. chance; y 4. chançaina / chanzaina; voz también germanesca con el mismo significado que la chanza anterior y fruto del cruce de ella con chanfaina 'guisado de bofes y otros ingredientes', 'mezcolanza' y 'rufianesca'. Pues bien, todo este despliegue conduce a la explicación de la única chanza que hoy prácticamente pervive (junto con sus derivados chancear y chancero), y que no parece haber existido hasta fines del XVI (los primeros testimonios son de Lope): 'dicho burlesco o gracioso', 'broma', 'burla'. Una explicación en la que encajan brillantemente todas las piezas del puzzle:

Esta chança / chanza, que el Diccionario académico actual define como "dicho festivo y gracioso", "hecho burlesco para recrear el ánimo o para ejercitar el ingenio", no puede ser formación regresiva de aquel chançón / chanzón olvidado siglo y medio antes de que chança surgiera con este significado alrededor de 1600 . Se perfila como heredera de chancha 'parlería, mentira' (< ital. ciancia), precariamente viva desde el siglo XV hasta entrado el XVII, y desaparecida al tiempo mismo que crecía chança / chanza. El cambio fonético chancha > chança / chanza pudo obedecer a simple disimilación; pero es más probable que lo apoyara decisivamente el contagio de chançoneta / chanzoneta, que poseía las acepciones comunes o afines 'dicho jocoso o festivo, ingeniosidad, pulla'. Chanzoneta estaba marcada como diminutivo por el sufijo; pero el total desuso del antiguo chanzón la había dejado sin base que la motivara: ¿de qué nombre era diminutivo? El instinto lingüístico de los hablantes la asoció con chancha y consolidó la disimilación chancha > chança o chanza, iniciada probablemente de manera espontánea. A fines del XVII no era Ayala Manrique el único en creer que chanzoneta fuese diminutivo de chanza: la masa anónima de los hispanohablantes lo venía dando por sentado, tácitamente, desde un siglo atrás. Hubo además otra interferencia: el chanzero mejicano de 1529 prueba que ya vivía entonces en el léxico español la otra chança / chanza, la procedente del francés chance 'azar, jugada del azar, suerte'. No podemos precisar cuándo pasó esta chança a significar la trampa del tahúr o la astucia del ladrón; pero nos consta, por el testimonio de Chaves [= Hidalgo], que ya lo había hecho antes de 1602. El engaño y la astucia de los maleantes entraron fácilmente en el área semántica de la burla: recuérdese cuántas veces los delitos contra la propiedad ajena se 
celebran como burlas en la novela picaresca. No es, por tanto, extraño que uno de los primeros ejemplos que poseemos de chança 'burla' pertenezca a un romance de germanía ${ }^{35}$.

Nos encontramos, así, con que la actual chanza puede ser resultado o sedimento de hasta tres ramas léxicas surgidas de tres diferentes étimos, pero enlazadas por una tupida red de afinidades semánticas que Lapesa desbroza con suma habilidad. Nótese muy especialmente, en lo que antecede, el sumo cuidado con que se apoyan las hipótesis en datos cronológicos, es decir, se hace verdadera historia lingüística y no malabarismos de etimología acrónica.

Para lo cual es imprescindible, claro está, manejar una documentación lo más rica posible. Tanto el trabajo que acabamos de comentar como las "Notas etimológicas y semánticas" de 1988 están realizados con los materiales reunidos por el Seminario de Lexicografía de la Real Academia Española ${ }^{36}$, de cuya extraordinaria riqueza y utilidad son nueva prueba. Sin esos materiales, una explicación tan diáfana como la que hemos expuesto no hubiera sido posible; sin la inteligencia de quien la desarrolla, tampoco.

Unos y otra se dan nuevamente la mano en un trabajo de circunstancias en que lo etimológico, entendido como mera determinación del origen, no plantea el menor problema. Se trata, de "Ínsula: palabra y aventura" (pp. 53-56), escrito (1980) para un número conmemorativo de la revista literaria del mismo nombre. El latinismo ínsula (también ínsola) nace en español cuando ya el otro elemento del doblete, isla, se halla bien asentado, y lo hace como sinónimo suyo, pero con referencia especial a entidades geográficas remotas; tras examinar ejemplos del XV y de libros de caballerías, observa Lapesa con sagacidad que "la palabra entró en el Siglo de Oro con aureola de connotaciones prestigiosas: sabor latino, nimbo de lejanía, ventana abierta a la imaginación, estímulo de empresas arriesgadas" (p. 55); por lo que se refiere a la literatura moderna pues solo literaria, y muy literaria, es la voz- el empleo de ínsula se ha limitado casi, como era previsible (pero la constatación no deja de ser oportuna), a recuerdos cervantinos. Lengua y literatura bellamente hermanadas —como tantas veces en la producción lapesiana- en este pequeño artículo, una de esas piezas a las que Yakov Malkiel gustaba de llamar "camafeos".

Para cerrar esta sección de estudios clasificados como etimológicos hemos de aludir brevemente a la intervención de Lapesa en la polémica sobre el origen de español, suscitada por "Español", palabra extranjera: razones y motivos (1970) de Américo Castro. La

\footnotetext{
${ }^{35}$ LH I, pp. 110-111. A propósito de la reinterpretación de chanzoneta como diminutivo de chanza señala Lapesa en nota: "Yakov Malkiel [...] percibió certeramente la asociación semántica antietimológica establecida entre chanzoneta y chanza, pero considera ésta descendiente sólo del francés, sin referirse a la herencia del ital. ciancia ni tener noticia del intermediario español chancha".

${ }^{36}$ Para las "Notas...", Lapesa señala además que la documentación preliteraria procede de lo que en esa ocasión denomina Contribución al primitivo léxico románico español, "reunido en 1927-1936 bajo la dirección de Don Ramón Menéndez Pidal en el Centro de Estudios Históricos y ampliado con la colaboración del Prof. Constantino García González, que espero publicar" (p. 65). Lexicografía e indagación etimológica, pues, se interrelacionan de manera fecunda en la obra de Lapesa.
} 
primera versión del artículo de Lapesa, "Sobre el origen de la palabra español" (pp. 79-86), apareció en 1971 en un periódico madrileño; por expreso deseo de su maestro figuró después, con adiciones y notas, como prólogo a Sobre el nombre y el quién de los españoles (1973); y fue de nuevo revisado, e incrementado con un apéndice, en $1983^{37}$, pues entre tanto se habían publicado nuevas e importantes contribuciones al tema. La de Lapesa no ha perdido el tono didáctico y la ponderación de su primera aparición periodística: explica y apoya con suma claridad el origen occitano del gentilicio - propuesto por Aebischer en 1948 - demuestra que si la denominación arraigó fue porque vino a llenar un vacío, y, en fin, razona muy sensatamente que "no debemos considerar desgracia nacional o desdoro el que español sea un provenzalismo" (p. 85). Se comprende la satisfacción de Castro por haber encontrado en su fiel discípulo un tan sereno y sólido puntal.

No era fácil rotular el conjunto de los tres trabajos que, en $L H I$, integran la sección segunda, "Lexicología y Semántica", los tres, por añadidura, con notorias implicaciones histórico-literarias. Es el primero de ellos "Símbolos y palabras en el Setenario de Alfonso X” (1980; pp. 115-134), y está destinado a abordar algunos aspectos no tratados por K. Vanderford en su edición (1945) de esa temprana y extraña obra ${ }^{38}$. No todos ellos conciernen al estudio del léxico, pero este aflora aquí y allá, como objeto de la atención del rey o por el hecho de que la obra registre, en los inicios mismos de la magna empresa alfonsí, "el vocabulario disponible en castellano para la exposición doctrinal" (p. 131). Me limitaré a recoger aquí la esclarecedora presentación que hace Lapesa del interés de Alfonso X por las palabras:

Si la naturaleza, la historia y los saberes están poblados de símbolos que el Rey Sabio escudriña con afán, es perfectamente explicable que se interesara con pasión por la etimología de las palabras, en el doble sentido de "significación verídica" y "procedencia de ellas". En el Setenario abundan ya definiciones cuidadosamente acuñadas que pueden competir en maestría con las que pululan en las grandes obras historiales y jurídicas ( $\mathrm{p}$. 129).

Lo cual no lleva a Lapesa a considerar al monarca como "lexicógrafo", como a otros apresuradamente ha llevado, con —no por reiterado más disculpable — patente desconocimiento de lo que tal designación implica. Praxis metalingüística, pero no lexicografía, es lo que hace el Rey Sabio, también cuando da rienda suelta a esa creencia que Lapesa tan atinadamente denomina "comunión de las lenguas", en virtud de la cual "una secuencia de fonemas ligada a un cierto significado en una lengua podía guardar oculto, como sentido simbólico en potencia, el significado que por designio divino había tenido o fuera a tener en otra lengua" (p. 130); así, no por casualidad la hostia de la eucaristía es de pan, pues pàn en griego significa 'todo', lo que muestra que "por ella [la hostia] rreçibimos cumplimiento de todo bien". Sorprendería conocer la tardía fecha en que se superó la tentación de incurrir en semejantes especulaciones "etimológicas".

\footnotetext{
${ }^{37}$ Para su inclusión en EHLE (pp. 132-137).

${ }^{38}$ Por ello, con buen criterio se incluyó el trabajo de Lapesa al frente de la reimpresión de dicha edición (Barcelona, Crítica, 1984). También se reproduce en EHLE (pp. 226-238).
} 
Los otros dos trabajos de la mencionada sección, ambos de 1972, están dedicados a los cultismos o latinismos semánticos de los dos poetas mayores del Renacimiento español: "El cultismo semántico en la poesía de Garcilaso" (pp. 135-151) y "Latinismos semánticos en la poesía de Fray Luis de León" (pp. 153-165). La riqueza de los materiales examinados es considerable, como rica y variada es la tipología de los mecanismos del préstamo que de ellos puede inferirse. El caso típico es aquel por el que un significante español, descendiente de uno latino por vía patrimonial o culta y dotado ya en la lengua de uno o varios significados, pasa a adoptar, por voluntad del poeta, otro más, característico de la voz latina o al menos del uso que de ella hacía un determinado autor; así, feliz ocurre en Garcilaso con el valor de 'fértil, feraz, fructífero' que tenía en latín felix. Otras veces, la voz española no procede exactamente de la latina, pero existe parentesco formal entre ambas; por ejemplo, enajenar vale 'apartar, alejar', también 'apartarse de la amistad o amor de alguno', acepciones que toma de alienare. Finalmente, puede ocurrir que el vocablo castellano y el latino no tengan ningún parentesco, pero compartan un significado básico, que basta como puente para el préstamo; es el caso de mantener 'satisfacer la avidez de los sentidos o del ánimo con el asombro producido por lo que perciben', que es copia de un uso metafórico de pascere en Virgilio. Los dos últimos ejemplos son también del poeta toledano, pero la casuística se incrementa con Fray Luis. En él, leño 'nave'

reproduce el uso latino de pinus, abies o trabs para referirse a navío; pero Fray Luis no lo imita valiéndose de pino ni de madero, sino de leño, y esta elección no es casual: le gno venía empleándose de antiguo en la poesía italiana con igual sentido. Los ejemplos abundan desde Dante y Petrarca y son frecuentes en autores casi contemporáneos del nuestro y leídos por él, como Bernardo Tasso (pp. 157-158).

Con lo que estaríamos, entonces, más bien ante un italianismo semántico inspirado a su vez por un latinismo del mismo carácter en la lengua toscana. Y el hecho de que entre los ejemplos luisianos analizados dominen claramente los verbos, a los que se fuerza a funcionar como sus homólogos latinos (desesperar se usa como transitivo con el sentido de 'perder las esperanzas de conseguir [algo]' — “el puerto desespero"-, calcando el latín d esperare honores, desperare pacem), legitima para hablar de latinismo sintáctico además de semántico. En cualquier caso, esos dos artículos de Lapesa tienen la rara virtud de haberse hecho de imprescindible lectura tanto para los estudiosos del léxico como, claro es, para los de la poesía de los Siglos de Oro.

Quedó fuera de la recopilación de 1992 un conjunto perfectamente armónico de trabajos que don Rafael tenía comprometidos para otro libro ( $E M C$, donde efectivamente se reúnen) y que podemos adscribir a la Lexicología en la orientación suscitada en Francia por Matoré y Dubois, orientación que ha dado sus principales frutos en el estudio del léxico político -pero no sólo- y de la que Lapesa ha de ser considerado primer y principal animador en España. Lo ha sido a través de la dirección de algunas tesis doctorales (las de $\mathrm{M}^{\mathrm{a}}$ Cruz Seoane, Doris Ruiz Otín o quien esto escribe ${ }^{39}$ ) y del importante conjunto de trabajos a que

\footnotetext{
${ }^{39}$ A ellas habrían de añadirse otras dirigidas por A. Zamora Vicente (C. Martín Gaite, P. Peira), E. de Bustos Tovar (J. F. García Santos), J. Mondéjar (Mª T. García Godoy), etcétera.
} 
me refiero. Con el antetítulo del primero y principal de ellos, "Ideas y palabras: del vocabulario de la Ilustración al de los primeros liberales" (1966-67, pp. 11-42), estaba formulando Lapesa el principio básico de esa orientación, desarrollado por él mismo, sin aspavientos teóricos pero con suma claridad y precisión, en un sucinto prólogo (en cierto modo programático) a la más temprana de aquellas tesis:

Este libro de María Cruz Seoane de Sueiro inaugura en la lingüística española un tipo de investigación llamado a prestar inestimable auxilio a la historia de las ideas y a la historia general. Consiste en acotar un sector del léxico vigente en un período histórico dado, precisar las afinidades significativas entre las palabras que lo constituyen, las diferencias conceptuales o afectivas que oponen unas a otras, la frecuencia o énfasis especial con que se usaron; y una vez trazada la estructura del campo léxico elegido, indagar la jerarquía de valores que refleja y diseñar la concepción del mundo a que corresponde ${ }^{40}$.

Aunque los frutos de la actividad investigadora de Rafael Lapesa en este campo hayan aparecido en diferentes momentos (y todos ellos en misceláneas de homenaje), su origen se remonta a la participación del autor en un Seminario de Estudios de Humanidades promovido en 1960 por Julián Marías en el seno de la Sociedad de Estudios y Publicaciones. Un valioso equipo multidisciplinar, al que Lapesa aportaba la visión del historiador de la lengua, se concentró por entonces, según ha explicado Marías, en el estudio de "un período abarcable y que tuviese significación para los problemas con los que nuestro país tendría que enfrentarse en el futuro cercano: el que va de 1750 a 1850"41. El grupo se disolvió en 1969, dejando tras sí algunos libros importantes para el estudio de una etapa hasta entonces poco atendida de la historia española ${ }^{42}$.

A los historiadores del léxico nos deparó con el tiempo, como digo, un haz de imprescindibles trabajos de Lapesa, dedicado el primero, el ya citado "Ideas y palabras..."43, al léxico de la Ilustración y del primer liberalismo, y los otros tres al de la época romántica. Basados en un selecto -y por fuerza selectivo- corpus de lecturas, densos y ricos tanto por las observaciones y comentarios como por el contingente mismo de las palabras que se examinan, estos trabajos abren innumerables vías de investigación, algunas apenas recorridas después. Nótese que los tres consagrados al período romántico, "El lenguaje literario en los años de Larra y Espronceda" (1984, pero redactado en 1977;

\footnotetext{
${ }^{40} \mathrm{En} \mathrm{M}^{\mathrm{a}} \mathrm{C}$. Seoane, El primer lenguaje constitucional español. (Las Cortes de Cádiz), Madrid, Moneda y Crédito, 1968, p. 15.

${ }^{41}$ Una vida presente. Memorias 2 (1951-1975), Madrid, Alianza, 1989, pp. 166-167.

${ }^{42}$ Además del ya citado de $\mathrm{M}^{\mathrm{a}}$ Cruz Seoane, me refiero a La España posible en tiempo de Carlos III (1963) de Marías, La visión de la realidad española en los viajes de don Antonio Ponz (1968) de Joaquín de la Puente, Teatro y sociedad en España (1780-1820) (1969) de Jorge Campos, etc., publicados todos ellos por la Sociedad de Estudios y Publicaciones en su Editorial Moneda y Crédito. Otros detalles sobre los componentes y actividades del Seminario se encontrarán en el citado volumen de las Memorias de Marías, pp. 166-168.
}

${ }^{43}$ Vio la luz en Asclepio. Archivo Iberoamericano de Historia de la Medicina, XVIII-XIX (1966-67) (Homenaje a Pedro Laín), pp. 189-218; también, en Boletín de la Academia Peruana de la Lengua, 1 (1967), pp. 67-104. 
pp. 67-11044), "Algunas consideraciones sobre el léxico político en los años de Larra y Espronceda" (1985, pp. 111-136) y "Palabras y cosas: el vocabulario de la vida social y la indumentaria durante el Romanticismo" (1989, pp. 137-154), exploran tres distintas parcelas del léxico que, sumadas, nos brindan un completo friso de la sociedad del momento; y que el antetítulo del tercero retoma la evocación o guiño que el de 1966-67 hacía a una posible extensión, desde el terreno geográfico y etnográfico al histórico, de los postulados inspiradores del método de "Wörter und Sachen".

Dichos trabajos sirvieron a su autor, además, para enriquecer notablemente algunas secciones de la Historia de la lengua española en su renovadísima edición - la 8 a - de 1980. A.sí, el epígrafe titulado "Vocabulario de la Ilustración, del Prerromanticismo y de los primeros liberales" 45 es en ella enteramente nuevo, y resume el estudio de similar título. Parecido carácter, en fin, tienen las secciones dedicadas al léxico en algunos trabajos de conjunto sobre el español moderno que Lapesa ha debido escribir para atender requerimientos diversos. Me refiero a "La lengua desde hace cuarenta años" (1963, para un número conmemorativo de Revista de Occidente) ${ }^{46}$, a "Tendencias y problemas actuales de la lengua española" $(1974)^{47}$ y a la original, valiosísima colaboración de Lapesa a un volumen de la Historia de España fundada por Menéndez Pidal, el dedicado a La Edad de Plata de la cultura española (1898-1936) ${ }^{48}$. Para acometer este último encargo, un Lapesa octogenario se enfrentó con brío a un período prácticamente no hollado por los historiadores de la lengua, cercano y ya lejano a un tiempo; al ocuparse del léxico, Lapesa se vale, como indicio, de la fecha de incorporación de ciertas voces a las sucesivas ediciones del diccionario académico a lo largo del período estudiado $(1899,1914,1925$, 1936), también de la escasa bibliografía disponible, o recurre — grata sorpresa para el lector de 1994- "a mis recuerdos personales, a anécdotas conocidas y hasta a canciones frívolas de antaño que atestiguan la vigencia de tal o cual palabra o locución en determinada fecha" (p. 358). El sabio filólogo, nunca envarado desde luego, se permite la licencia, en esta prodigiosa contribución de la plena madurez, de citar de vez en cuando un cuplé, e imaginamos el brillo entre malicioso y nostálgico de su mirada al hacerlo. Un gran poeta lo vio certeramente: "Ninguno más humano".

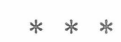

\footnotetext{
${ }^{44}$ Tanto este como "Ideas y palabras..." incorporan, en $E M C$, apéndices bibliográficos actualizados.

${ }^{45}$ Madrid, Gredos, 1980, pp. 429-434.

${ }^{46}$ Incluido en EMC (pp. 397-413) con el título "La lengua entre 1923 y 1963".

${ }^{47}$ Escrito para un curso dirigido por el mismo Lapesa en el Instituto de Ciencias del Hombre y cuyas lecciones se reunieron en libro en 1977; en este trabajo las referencias al léxico, que no faltan, son algo menos abundantes, pues otra intervención del ciclo, la de Manuel Seco, estaba íntegramente dedicada a "El léxico de hoy". El trabajo de Lapesa se incluye en EMC (pp. 422-459) con "muchas adiciones y enmiendas".

${ }^{48}$ Tomo XXXIX, vol. II: Letras, ciencia, arte, sociedad y culturas, Madrid Espasa-Calpe, 1994. El capítulo de Lapesa, "La lengua", ocupa las pp. 4-40, y se reproduce, en versión más completa, en $E M C$ : "Nuestra lengua en la España de 1898 a 1936" (pp. 343-396).
} 
En la primera parte de este trabajo hube de citar a menudo uno excelente de Manuel Seco. En otra semblanza, refiriéndose a la denodada entrega de Lapesa al Diccionario histórico, escribió el mismo Seco con toda justeza: "La gran lección de Lapesa en el Seminario ha sido su renuncia a miles de horas de su investigación personal en beneficio de la monumental tarea colectiva" 49 . Afortunadamente, en el caso de Lapesa, la laboriosidad, aliada con la longevidad, han dado para mucho, y, aun con esa renuncia, tanto la obra individual como la colectiva han rendido frutos que rayan a la máxima altura. Ojalá sepamos seguir en todo su ejemplo.

49 “Lapesa, la lección diaria”, BRAE, LXVIII (1988), p. 32. 